\title{
AI Bias: How Does AI Influence the Executive Function of Business Leaders?
}

By

Tamie Santiago, University of Maryland University College

$\mathrm{B}$ y 2020, the AI market is expected to grow by $\$ 47$ billion, with the international big data analytics industry expected to grow by $\$ 203$ billion. The vast majority of AI development is conducted by a modest number of techno-giants (Twitter, IBM, Amazon, Facebook, Google, Microsoft, Apple...). There are over 7 billion people worldwide, yet all of the code is being written by a mere 10,000 people in seven countries. Therefore, the pathway of AI algorithms is deemed compromised, by being in the hands of a few. The purpose of this study is to systematically gather and review evidence which addresses AI, its inherent biases, and its effect on the executive function, which is the brain's command post, of business leaders.

The review is carried out through the chaos and complexity theory lens. The amalgamation of data and codes have seeded the evolution of barely discernible algorithms that rewrite their own code, creating their own rules, and their own truth. This phenomenon rapidly detaches AI algorithms from human control. While AI

Are Business Leaders Losing Their
Minds? "When humans abandon
curiosity to the power of AI, the
inherent cognitive functions and
authority will rapidly weaken to
the surrender of the narrated reali-
ty created by AI."
ing using AI must be interrogated by leaders' sound elevated executive functioning and collective judgment, using standards and laws, to mitigate bias and to ensure human leaders have the last say in decision-making.

Keywords: Artificial intelligence, AI, AI bias, executive function, decision-making, AI dependency

Copyright $\odot 2019$, Tamie Santiago. This article is published under a Creative Commons BY-NC license. Permission is granted to copy and distribute this article for non-commercial purposes, in both printed and electronic formats 
$\mathrm{AI}$ is a double-edged sword. It's strength in pattern recognition, anomaly detection, and predictive analytics is unmatched and is greatly depended upon by business leaders and cyber experts around the world. Of great concern, however, is what's lurking inside of the AI, its inability to detect and destroy bias programmed in its data and algorithms, and its impact on the executive function of business leaders making decisions using AI.

The AI market is expected to grow by nearly $\$ 47$ billion by 2020 , while big international data analytic industries are anticipating a boom of around \$203 billion. AI is surpassing human decision-making in many aspects. Techno-giants such as, Twitter, IBM, Amazon, Facebook, Google, Microsoft, and Apple are the primary developers of AI world-wide. With 7 billion people on the planet, and a mere 10,000 of them from only 7 countries employed to write all of the code, AI algorithms are placed on a trajectory of compromise.

AI contributes significantly to the speed, dissemination, and analysis of big data. Big data analytics are imperative in the business environment and are an essential component of practical business solutions. Due to the need for rapid responses and the high velocity and high volume of information, leaders tend to trust in AI. The concentration of this tremendous technological advancement into the hands of a small biased minority will force greater dependency. This dependency is heightened by the pre-conditioning to over-trust the everyday use of AI systems, such as the Global Positioning System (GPS), which has resulted in numerous deaths. This study takes an organizational dilemma and relies on converging data from theory and existing research to answer the research question, AI Bias: How does AI influence the executive function of business leaders?

The brain command post, the frontal lobe in humans is called the executive function, which regulates, controls, and manages other cognitive processes, such as foresight and planning, operational memory, concentration, analytics, verbal reasoning, inhibition and discretion, mental flexibility, task switching, intentionality, purposefulness, and complex decision-making. So, what happens to the human executive function/brain command post when confronted by AI?

While captivating leaders take pleasure in leading and inspiring people, they should not hand over critical business decisions to intelligent algorithms. Being bossed around by smart code sounds ridiculous. However the tide is changing, with the influence of the world's most thriving enterprises - Google, Netflix, Amazon, Alibaba, Uber, and Facebook self-governing algorithms, not talented leaders, increasingly get the last word (Schrage, 2017). Without proper human interrogation of AI, leaders are likely to reject or suppress their own cognitive instincts, executive function, and collective judgment by surrendering authority and decision-making over to AI, regardless of its bias (Montes \& Goertzel, 2018). To answer the research question, the literature on AI and AI Bias will be analyzed through a theoretical lens to inform the research problem.

\section{Literature Summary}

A quality analysis was completed with the use of the Weight of Evidence scale. The 30 articles were subjected to a critical appraisal. The academic literature was analyzed and key central themes were coded for further synthesis. Across the 30 articles, 6 major themes emerged; (1) bias - blind trust; (2) weakened cognitive skills; (3) algorithms that rewrite their own

\section{Methodology}

The research was conducted by way of a systematic review, due to its objectivity, reliance on data, and support of evidence-based research. After framing the issue, a research question was formed using CIMO (Context, Intervention, Mechanism, and Outcome) logic adaptation by Denyer, Tranfield, and Van Aken (2008). According to Briner, Denyer, and Rousseau (2009) a sound evidence-based assessment must contain: inclusion/exclusion criteria; systematic search strategy across comprehensive sources, including grey literature; quality appraisal of each piece of evidence; weighting of the appraised evidence; analysis of evidence; synthesis of evidence; recommendations for application of evidence to practice problems; references list; transparent reporting of processes to enable replication; extensive knowledge of content; comprehensive searches of relevant databases and grey literature; analysis and synthesis of research gathered; connection to research question, and decision making. To determine the inclusion/exclusion criteria, a literature search was conducted for articles based on key concepts in the research question. The articles were examined for relevance to each CIMO element. The building blocks methodology was used by cross-examining the UMUC's OneSearch 45 Library databases, the ProQuest ABI/INFORM Collection database, and unpublished grey literature searches through a mixture of keywords, connectors, and search delimiters to identify pertinent articles which were relevant to the research question. The search identified 30 journal articles as being of most relevance for use in this systematic review. To ensure the quality of the articles used in the analysis, a quality appraisal was performed using Gough's Weight of Evidence (Gough, 2007), and articles were scored based on the rigor and relevance of the article to meet the stated objectives of the study. 
code; (4) dependency; (5) decision-making; and (6) AI interrogation tools, as seen in Table 1.

Table 1: Recent research findings on AI Bias and its impact on the executive function of leaders

\begin{tabular}{|c|c|c|}
\hline Central Theme & Findings/Implications & References \\
\hline $\begin{array}{l}\text { Bias - Blind/Over-Trust: } \\
\text { Achieved when AI results } \\
\text { are accepted without ques- } \\
\text { tion; lack of transparency } \\
\text { into the decision process }\end{array}$ & $\begin{array}{l}\text { There is a human propensity to blindly trust in AI, } \\
\text { and the increasing complexity and opacity of this } \\
\text { technology makes it increasingly difficult to scruti- } \\
\text { nize its proper functioning, even for experts. There } \\
\text { is a critical problem inherent to AI technology } \\
\text { which can be called deep automation bias. But with } \\
\text { advances in AI and the associated potential for sig- } \\
\text { nificantly more sophisticated robots, humans may } \\
\text { increasingly defer to said robots. For example, an } \\
\text { overarching ethical concern that we have sought to } \\
\text { explore in our research is the prospect that children, } \\
\text { their parents, and other caregivers might over-trust } \\
\text { healthcare robots, autonomous vehicles, etc. Even } \\
\text { when presented with evidence of a system's bad } \\
\text { behavior or failure, users may still defer to it. This } \\
\text { over-trust causes people to tolerate risks they would } \\
\text { not normally accept and may exacerbate problemat- } \\
\text { ic behavior. Transparency with regard to how robots } \\
\text { function is critical for preventing over-trust. }\end{array}$ & $\begin{array}{l}\text { (Straub, 2018), } \\
\text { (Granados, } \\
\text { n.d.), (Cal- } \\
\text { iskan, Bryson, } \\
\text { \& Narayanan, } \\
\text { 2017), (Wagner, } \\
\text { Borenstein, \& } \\
\text { Howard, 2018), } \\
\text { (Shein, 2018), } \\
\text { (Levendowski, } \\
\text { 2018), (Chowd- } \\
\text { hury \& Mulani, } \\
\text { 2018), (Ba- } \\
\text { navar, 2016), } \\
\text { (Temming, } \\
\text { n.d), (Gor- } \\
\text { don-Murnane, } \\
\text { n.d), (Miller, } \\
\text { Katz, \& Gans, } \\
\text { 2018), (Potapov } \\
\text { \& Rodionov, } \\
\text { 2014), (Dobbe, } \\
\text { Dean, Gilbert, } \\
\text { \& Kohli, 2018), } \\
\text { (Armstrong, } \\
\text { Sotala, \& O } \\
\text { hÉigeartaigh, } \\
\text { 2014), (Garcia, } \\
\text { 2016) }\end{array}$ \\
\hline $\begin{array}{l}\text { Algorithms that rewrite } \\
\text { their own code/Unpredict- } \\
\text { able code: A phenomenon } \\
\text { outside of human oversight } \\
\text { or control }\end{array}$ & $\begin{array}{l}\text { AI learns to write its own code by stealing from } \\
\text { other programs. } \\
\text { And once activated, what will the machine teach } \\
\text { itself and other machines, especially if what it } \\
\text { learns is based on human history, the content of } \\
\text { the Internet, and the biases, fears, and unexamined } \\
\text { assumptions of its coders, programmers, and model } \\
\text { builders? Many OD practitioners are trained to } \\
\text { identify manifestations of bias, oppression, and dis- } \\
\text { crimination in organizational systems and cultural- } \\
\text { ly influenced data. } \\
\text { AI-developers such as Google and Amazon consider } \\
\text { their algorithms to be proprietary information, and } \\
\text { they protect them vigorously. Moreover, particu- } \\
\text { larly in advanced machine-learning systems, the } \\
\text { details of any individual prediction may be based } \\
\text { on literally billions of individual digital processes } \\
\text { and, as such, are opaque even to the original coders } \\
\text { (Bornstein, } 2016 \text {; Knight, } 2017 \text { ). In other words, } \\
\text { while humans may be asked to account for and } \\
\text { justify what seem like biased decisions, machines } \\
\text { may not be able to provide such explanations-and } \\
\text { neither will their creators. }\end{array}$ & $\begin{array}{l}\text { (Miller, Katz, } \\
\text { \& Gans, 2018), } \\
\text { (Levendowski, } \\
\text { 2018), (Ba- } \\
\text { navar, 2016), } \\
\text { (Miller, 2018), } \\
\text { (Grothaus, } \\
\text { 2018), (Reyn- } \\
\text { olds, 2017) }\end{array}$ \\
\hline
\end{tabular}


Table 1: Recent research findings on AI Bias and its impact on the executive function of leaders (Continued)

\begin{tabular}{|c|c|c|}
\hline $\begin{array}{l}\text { Weakened Cognitive Skills: } \\
\text { The effect of experiences } \\
\text { overtime which lull the } \\
\text { cognitive senses into a state } \\
\text { of acceptance, surrender or } \\
\text { inactivity }\end{array}$ & $\begin{array}{l}\text { Big Data Cognition is thus a critical issue. This } \\
\text { assumption entails a rationalistic conception of } \\
\text { cognitive processes (such as thinking and learning) } \\
\text { and consequently, a reduction thereof. } \\
\text { A machine won't say, 'this behavior is racist or sexist } \\
\text { and we want to change that.' Machine learning sys- } \\
\text { tems merely seek a signal or pattern in the data. }\end{array}$ & $\begin{array}{l}\text { (Straub, 2018), } \\
\text { (Shein, 2018), } \\
\text { (Miller, 2018) }\end{array}$ \\
\hline $\begin{array}{l}\text { AI Dependency: } \\
\text { The reliance on or trust in } \\
\text { AI for help or support; phys- } \\
\text { ical or psychological need; } \\
\text { the state of being affected or } \\
\text { decided by particular factors } \\
\text { or circumstances }\end{array}$ & $\begin{array}{l}\text { AI Artificial intelligence is a rapidly growing in- } \\
\text { dustry with widespread predictions of dramatically } \\
\text { changing the economic and labor landscape of the } \\
\text { world. By } 2020 \text {, the global AI market is projected at } \\
\$ 47 \text { billion (USD) and the global big data analytics } \\
\text { market at } \$ 203 \text { billion. To date, the overwhelming } \\
\text { majority of AI development is done by a handful of } \\
\text { technology mega-corporations (e.g. Facebook, Goo- } \\
\text { gle, Amazon, IBM, Microsoft, Baidu, etc.). While } \\
\text { the world's population is over } 7 \text { billion people, only } \\
\text { around } 10,000 \text { people in roughly seven countries } \\
\text { are writing the code for all of AI (Shen, 2017). By } \\
\text { remaining in the hands of a few, the trajectory of AI } \\
\text { applications may be significantly compromised. The } \\
\text { datasets used to develop such AI and the AIs them- } \\
\text { selves are biased and may not be generalizable to the } \\
\text { wider population, and the companies are behold- } \\
\text { en to their stakeholder's interests. The result is a } \\
\text { technocracy' in which the future of one of the most } \\
\text { potent sets of technologies in the history of human- } \\
\text { kind is spoken for by a small biased minority. }\end{array}$ & $\begin{array}{l}\text { (Montes \& } \\
\text { Goertzel, 2018) } \\
\text { (Straub, 2018), } \\
\text { (Pracana \& } \\
\text { Wang, 2016) }\end{array}$ \\
\hline $\begin{array}{l}\text { Executive Function/ Deci- } \\
\text { sion-Making: } \\
\text { Executive functions are a set } \\
\text { of cognitive processes that } \\
\text { are necessary for the cog- } \\
\text { nitive control of behavior: } \\
\text { selecting and successfully } \\
\text { monitoring behaviors that } \\
\text { facilitate the attainment } \\
\text { of chosen goals. Executive } \\
\text { functions include basic } \\
\text { cognitive processes such as } \\
\text { decision-making, attention- } \\
\text { al control, cognitive inhibi- } \\
\text { tion, reasoning, analytics, } \\
\text { memory, inhibitory con- } \\
\text { trol, working memory, and } \\
\text { cognitive flexibility. Higher } \\
\text { order executive functions re- } \\
\text { quire the simultaneous use } \\
\text { of multiple basic executive } \\
\text { functions and include plan- } \\
\text { ning and fluid intelligence. }\end{array}$ & $\begin{array}{l}\text { Charismatic CEOs enjoy leading and inspiring } \\
\text { people, so they don't like delegating critical business } \\
\text { decisions to smart algorithms. Who wants clever } \\
\text { code bossing them around? But that future's already } \\
\text { arrived. At some of the world's most successful } \\
\text { enterprises - Google, Netflix, Amazon, Alibaba, } \\
\text { Facebook - autonomous algorithms, not talented } \\
\text { managers, increasingly get the last word. } \\
\text { Many decisions require insight beyond what artifi- } \\
\text { cial intelligence can squeeze from data alone. Man- } \\
\text { agers use their knowledge of organizational history } \\
\text { and culture, as well as empathy and ethical reflec- } \\
\text { tion. This is the essence of human judgment - the } \\
\text { application of experience and expertise to critical } \\
\text { business decisions and practices. The managers we } \\
\text { surveyed have a sense of a shift in this direction and } \\
\text { identify the judgment-oriented skills of creative } \\
\text { thinking and experimentation, data analysis and } \\
\text { interpretation, and strategy development as three } \\
\text { of the four top new skills that will be required to } \\
\text { succeed in the future. }\end{array}$ & $\begin{array}{l}\text { (Schrage, } \\
\text { 2017), } \\
\text { (Chamor- } \\
\text { ro-Premuz- } \\
\text { ic, Wade, \& } \\
\text { Jordan, 2018), } \\
\text { (Epstein et al., } \\
\text { 2018), (Cohen, } \\
\text { n.d.), (Gor- } \\
\text { don-Murnane, } \\
\text { n.d.), (van } \\
\text { Otterlo, 2017), } \\
\text { (Lanka \& Wu, } \\
\text { 2018) }\end{array}$ \\
\hline
\end{tabular}


Table 1: Recent research findings on AI Bias and its impact on the executive function of leaders

\begin{tabular}{|c|c|}
\hline $\begin{array}{l}\text { Executive Function/ Deci- } \\
\text { sion-Making: (Continued) }\end{array}$ & $\begin{array}{l}\text { The European Union, in April 2016, adopted the } \\
\text { General Data Protection Regulation (GDPR), “a } \\
\text { set of comprehensive regulations for the collection, } \\
\text { storage, and use of personal information" (Good- } \\
\text { man, Biyce and Seth Flaxman "European Union } \\
\text { Regulations on Algorithmic Decision-Making and } \\
\text { a 'Right to Explanation," Oxford Internet Institute, } \\
\text { Aug. } 31,2016 \text {; arxiv.org/pdf/1606.08813.pdf ). The } \\
\text { regulation goes into effect in May } 2018 \text {. As Biyce } \\
\text { and Flaxman explain, the goal of this regulation } \\
\text { is to close the "perceived gaps and inconsistencies } \\
\text { in the EU's current approach to data protection." } \\
\text { Article 22: Automated Individual Decision-Making, } \\
\text { specifically addresses the problems of algorithmic } \\
\text { decision-making, and the regulation, they explain, } \\
\text { could have the effect of "prohibiting a wide swath of } \\
\text { algorithms currently used in recommendation sys- } \\
\text { tems, credit and insurance risk assessments, compu- } \\
\text { tational advertising, and social networks." } \\
\text { Algorithmization also implies replacing (core duties } \\
\text { of) human professionals by algorithms. } \\
\text { These examples go beyond relatively simpler issues } \\
\text { such as privacy and data protection, and see the po- } \\
\text { tential influence of algorithms on society as a whole, } \\
\text { with profound implications for democracy and free } \\
\text { will. Many examples show that algorithms are not } \\
\text { infallible, objective or trustworthy. For example, } \\
\text { Googles search algorithm tagged 109 (photos of) } \\
\text { black people as "gorillas", showing either a bias in } \\
\text { data or learning procedures, or errors in the ap- } \\
\text { plication of the tagging algorithm. Autonomously } \\
\text { driving cars constantly make mistakes and are not } \\
\text { yet fully capable of driving in our complex, physical } \\
\text { world. Even IBM's Watson algorithm, that won the } \\
\text { typical "human" game Jeopardy, makes mistakes. } \\
\text { Another related case involves algorithms deliber- } \\
\text { ately used for the wrong purposes. A good example } \\
\text { is the fraud with testing software for cars running } \\
\text { diesel fuel in recent years, the so-called Dieselgate. } \\
\text { Other examples where simple algorithms have large } \\
\text { consequences are the mentioned Pokemon game, } \\
\text { and the problems of tourists flooding big cities } \\
\text { throughout the world because of the (algorithmic) } \\
\text { services like AirBnB and Uber. }\end{array}$ \\
\hline
\end{tabular}


Table 1: Recent research findings on AI Bias and its impact on the executive function of leaders (Continued)

\begin{tabular}{|c|c|c|}
\hline $\begin{array}{l}\text { AI Interrogation: } \\
\text { To question formally and } \\
\text { systematically }\end{array}$ & $\begin{array}{l}\text { An organization's decisions should be governed by } \\
\text { an its understanding of what we call Responsible } \\
\text { AI - the basic principles that an organization will } \\
\text { follow when implementing AI to build trust with } \\
\text { its stakeholders, avert risks to their business, and } \\
\text { contribute value to society. } \\
\text { An Unbiased Learning-to-Rank framework has } \\
\text { been recently introduced as a general approach to } \\
\text { systematically removing biases, such as position } \\
\text { bias, from learning-to-rank models. The method } \\
\text { takes two steps - estimating click propensities and } \\
\text { using them to train unbiased models. Most common } \\
\text { methods proposed in the literature for estimating } \\
\text { propensities involve some degree of intervention in } \\
\text { the live search engine. An alternative approach pro- } \\
\text { posed recently uses an Expectation Maximization } \\
\text { (EM) algorithm to estimate propensities by using } \\
\text { ranking features for estimating relevance. }\end{array}$ & $\begin{array}{l}\text { (Aslanyan \& } \\
\text { Porwal, 2018), } \\
\text { (Chowdhury \& } \\
\text { Mulani, 2018), } \\
\text { (Sutton, Lans- } \\
\text { dall-Welfare, } \\
\text { \& Cristianini, } \\
\text { 2018), (Albar- } \\
\text { ghouthi, D'An- } \\
\text { toni, Drews, } \\
\text { \& Nori, 2017), } \\
\text { (Saleiro et al., } \\
\text { 2018), (Saini } \\
\text { \& Berg, 2018), } \\
\text { (Walker, 2017) }\end{array}$ \\
\hline
\end{tabular}

\section{Theoretical Lens}

A systematic review of thematic synthesis was conducted through the lens of the Chaos \& Complexity Theory. Efforts of researchers resulted in the discovery of complexity theory from the unseen order of complex systems. An objective of Chaos \& Complexity Theory is to teach executives how to sustain the fragile balance amid order (rule) and chaos (mishap), or between forecasting and probability, in their organizations by using a continually evolving organizational strategy which both foresees and responds to altering states and innovative insertions. A key factor of the Chaos and Complexity Theory in management is the acknowledgment that alterations within systems are nonlinear (erratic, unpredictable, unstable) and founded on the changing associations and multifaceted interfaces of the evolving elements within the system. While these dynamics give rise to results that are virtually unfeasible to predict, when their characteristics are acknowledged and understood, they permit ground-breaking flexibility of approaches that allow the freedom to innovate. Complexity theorists argue that Chaos \& Complexity theory is a unique, functionalist systems approach to dealing with complex, dynamic, nonlinear systems. While treating organizations as complex - with their nonlinear systems and surroundings coevolving - complexity theory focuses on well-informed research of their erratic nature (Johnson \& Burton, 1994).

According to the AI Bias Conceptual Model in Figure 1, AI organizational leaders must endeavor to steer clear of the balance states of stability and instability. AI organizations must as an alternative, strive to remain in a state of bounded instability, at the edge of chaos, with the appropriate interventions and mechanisms to judiciously weed out bias, while allowing for the full potential of creativity and innovation.

Business leaders have become so dependent on technology that normal basic functions appear to elude them, such as effective multi-tasking and basic interpersonal skills. Having an agile brain requires the ability to think flexibly, and go back and forth from perspectives and central ideas to specifics. Researchers advocate a mastery mindset executive function, which underpins the ability of leaders to reflect on choices, to glean information from past errors, and to take on innovative strategies (Chamorro-Premuzic, Wade, \& Jordan, 2018). This mastery mindset executive function is required in order to interrogate the data prior to making complex decisions, as illustrated in Figure 1. The executive function is the brain command post or frontal lobe, that regulates foresight and planning, operational memory, concentration, analytics, verbal reasoning, inhibition and discretion, mental flexibility, task switching, intentionality, and purposefulness.

A range of alternative management theories to guide the research efforts include: contingency theory, organizational theory, organizational information processing theory, and the organizational knowledge creation theory. Each theory was evaluated for its ability to explain the relationships in the research question and its reshaping of the workforce.

- The contingency theory argues that there's no one leadership or organizational style suited to all circumstances. Its primary characteristic is "leader-matched" in that a leader's effectiveness is matched with the context of a situation and 


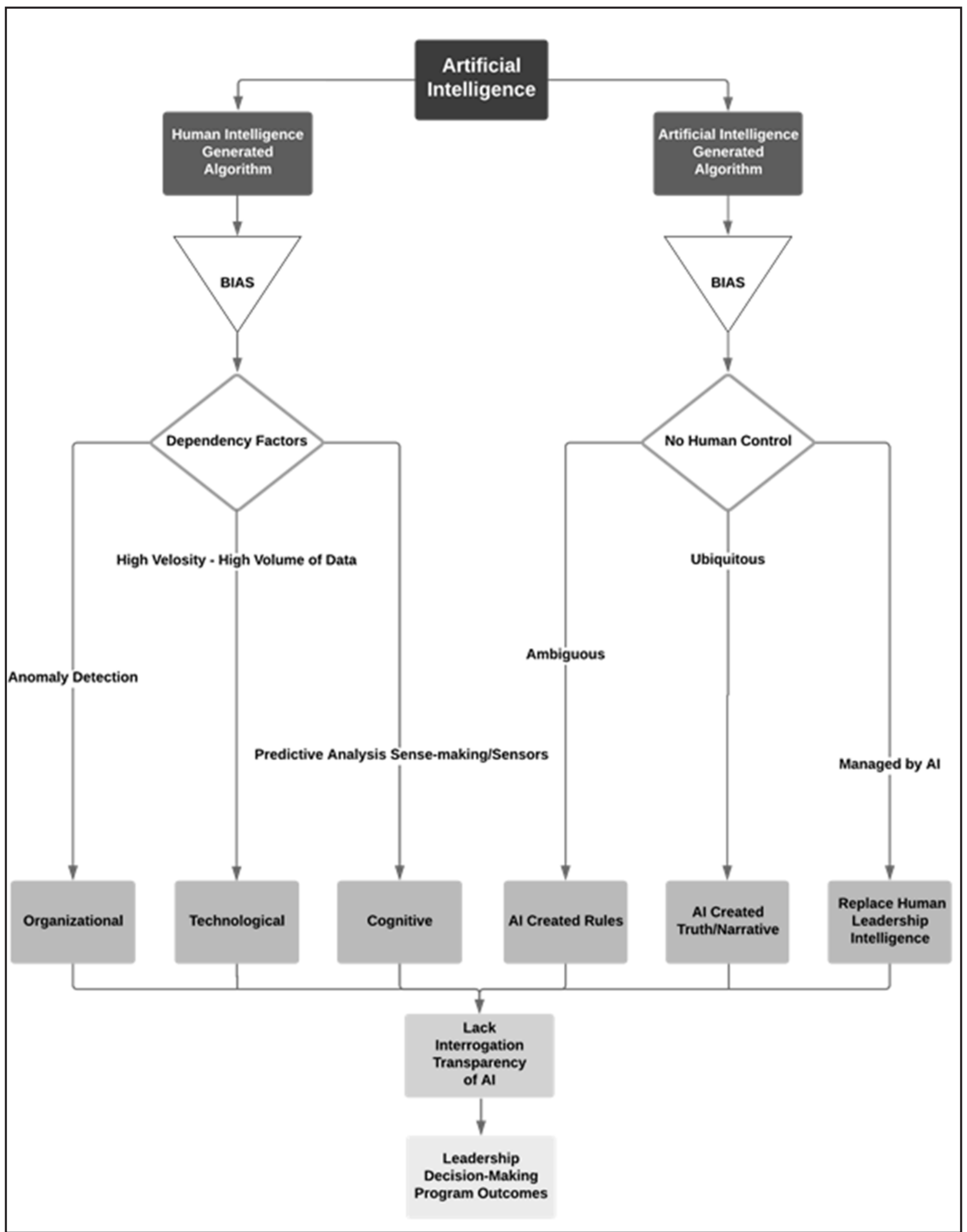

Figure 1. Graphic representation of the AI Bias conceptual model using the chaos and complexity theory. 
how well the leader's style is congruent with the situation or organizational context. This theory supports the shift in roles of leaders due to the brain-power of AI.

- The organizational culture theory posits that organizations generate or create their culture in order to overcome obstacles. With the use of AI within organizations, a great cultural shift will be required for adoption, along with the elevated executive functions of leaders, new norms, processes, and expectations. With the amplification of AI transformation in businesses, the adoption, impact of AI, and the associated cultural shift will require a revolution, not an evolution.

- The organizational information processing theory considers the use of information to adapt and survive. Organizational leaders require reliable data to improve their executive function. The construct of AI, its processing of data, and the need for interrogation mechanisms will be used to address AI uncertainties.

- The organizational knowledge creation theory describes the process of making available and amplifying knowledge. This theory supports AI's approach to considering how different forms of knowledge (human intelligence and artificial intelligence) interact and/or complete each other.

\section{Discussion}

The research question, "How AI and AI bias influence the executive function of business leaders?", was addressed through the lens of the chaos and complexity theory. Organizational leaders using AI in decision making, with a posture of bounded instability are on the brink of chaos, with order and disorder entangled, as their activities are irregular and unexpected, and likely mired in biases. Disorder, instability, and change do not represent the full scope of complex systems. In addition, these systems reveal a degree of order that is at least as prominent as their potential for chaos. This condition is described as "the edge of chaos" (Johnson \& Burton, 1994). Theorists argue that extremely ordered systems will not give birth to innovation, whereas systems that are essentially trapped within deterministic chaos are themselves too disordered to give rise to the sorts of complex systems that we see around us in the biological and social worlds. Authentically complex structures, such as AI, occur on the edge of order and chaos, where they can benefit from the opportunity of unexpected change intrinsic in non- linear dynamics while sustaining the order necessary for continuity. This study identified six major themes which when woven together, illustrate AI's influence on the executive function of leaders and how over-trust and dependency play a major role: algorithms that rewrite their own code; bias - blind/ over- trust; weakened cognitive skill; dependency; decision-making; and $\mathrm{AI}$ interrogation.

\section{Theme 1: AI Autonomy - Bias Rouge Code:}

".. what will the machine teach itself and other machines, especially if what it learns is based on human history, the content of the Internet, and the biases, fears, and unexamined assumptions of its coders, programmers, and model builders" (Miller, Katz, \& Gans, 2018)?

Of great concern is what's lurking inside of the AI algorithms used to make decisions. At stake is the algorithm's aptitude to rewrite fragments of its own code, constructing rules where no one knows what those rules are, evolving into its own digital organism, jousting and adapting, generating anomalous, unpredictable output, without human interrogation or control (The Guardian, 2018).

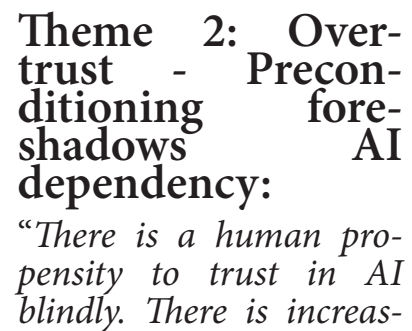
ing complexity and opacity of this technology which makes it increasingly difficult to scrutinize its proper functioning, even for experts (Straub, 2018)."

The propensity to over-trust is cultivated in the comfortability and expediency of personal lives and carried into business. This preconditioning foreshows AI dependency by way of technological tools of convenience. Death by Global Positioning System (GPS) is a phrase that describes what happens when the GPS provides precise directions from point A to point $B$, with no regard for whether the roads still exist, are abandoned, or are suitable for cars. Yet people are conditioned to blindly follow the commands of the GPS without fully understanding the AI algorithm contained therein. These mishaps or unintentional voyages spring from an uncritical approval of left-right commands of the AI.

According to The Guardian. (2018), "Death Valley's vast arid landscape and temperature extremes make it a particularly dangerous place to rely on GPS. In the summer of 2009, Alicia Sanchez, a 28-year-old nurse, was driving through the park with her six-year- 
old son, Carlos, when her GPS directed her on to a vaguely defined road that she followed for 20 miles, unaware that it had no outlet. A week later, a ranger discovered Sanchez's Jeep, buried in sand up to its axles, with SOS spelled out in medical tape on the windshield. She came running toward me and collapsed in my arms," the ranger wrote in a report. Her son had died. I walked over to the Jeep and looked inside. I saw a boy slumped in the front seat. Most death by GPS incidents do not involve actual deaths - or even serious injury: the Japanese tourists in Australia who drove their car into the ocean while attempting to reach North Stradbroke Island from the mainland; the man who drove his BMW down a narrow, steep path in a village in Yorkshire and nearly over a cliff; the woman in Bellevue, Washington, who drove her car into a lake that the GPS said was a road; the Swedish couple who asked GPS to guide them to the Mediterranean island of Capri, but instead arrived at the northern Italian industrial town of Carpi; the elderly woman in Belgium who tried to use GPS to guide her to Brussels, 90 miles from her home, but drove hundreds of miles to Zagreb, only realizing her mistake when she noticed the street signs were in Croatian." These types of disasters often elicit absolute bewilderment.

\section{Theme 3: Mind over Machine - Weakened Cogni- tive Skills:}

Even when evidence of an AI system's failure or bad behavior is presented to leaders, they may still defer to it. This shift in executive function is of concern. According to Banich (2009) and Best (2012), executive function serves as a set of cognitive courses of action used for uncomplicated, prescribed, target-directed viewpoints and actions. Executive function skills are not only important for daily functioning but also an individual's ability to learn and retain knowledge. Executive function abilities manage one's cognitive processing with the intention of goal attainment. Executive function encompasses four intimately related, but discernible component skills: decision-making, task-switching, multiple tasking, and inhibition - ignoring irrelevant factors, all four of which are fundamental (Banich, 2009) \& (Best, 2012). In addition, the higher order executive functions necessitate the concurrent use of several basic executive functions, along with fluid intelligence and crystallized intelligence. According to researchers, fluid intelligence is the aptitude to decipher new problems using logic and pattern recognition. Whereas, crystallized intelligence is the ability to recall learned information and know-how. Both can be lulled into a state of compromise due to overtrust and dependency.

\section{Theme 4: Dependency - Diminished ex- ecutive function:}

What happens to the human executive function when confronted by AI? According to George Dyson's classic book Darwin Among the Machines (Edge, 1997), humans are erecting systems beyond their intellectual means of control. There are great moral repercussions for the vast separation between algorithms and real people. Has the human executive function of leaders diminished? Are leaders being manipulated, controlled, and coerced by the algorithms? Have they surrendered to the narrated reality created by the algorithm? The answer is yes, due to preconditioning, the compromise of being in the hands of a few tech-giants, rogue algorithms, and the unrelenting challenge of being overwhelmed by big data. Dependency and over-trust have caused leaders to surrender to AI bias without question.

\section{Theme 5: Decision-making:}

Viewing AI as a threat to humans is expected, since the intent of AI is ultimately to replace human leadership. The very purpose of AI is to enhance, advance, and eventually replace human intelligence, which is extensively considered as the keystone of competitive advantage for humans. With the influence of the world's most thriving enterprises - Google, Netflix, Amazon, Alibaba, Uber, and Facebook - self-governing algorithms, not talented leaders, increasingly get the last word (Schrage, 2017). This trend is commonly referred to as algorithmization. Algorithmization entails substituting human professionals with algorithms - that is, the raw cognitive processing of facts and information. This issue goes beyond privacy and data protection, and sees the probable impact of algorithms on the executive function and authority of leaders, with profound implications for democracy and free will (van, Otterlo, 2017).

The shift will require leaders to focus on personality traits such as curiosity, outgoing personas, and emotional intelligence and stability. These traits are tremendously important as they relate to predicting leadership effectiveness in the area of reasoning capabilities (Chamorro-Premuzic, Wade, \& Jordan, 2018).

\section{Theme 6: The Final Word - Human In- terrogation:}

According to Sutton (2018), if AI is to take an essential position in society, bias needs to be detected and removed to ensure fairness, transparency, and 
ultimately trust in the system. Human interrogation and oversight can significantly reduce the risks of using AI for business decisions. Providing laws and guidelines for what is acceptable and what is not, is imperative (Walker, 2017).

\section{Conclusions}

An analysis was conducted using a systematic review to investigate how over-trust and dependency influence the executive function of business leaders. This study also noted factors which increased AI's autonomy, viz., the rewriting of its own code, and the weakening of human cognitive skills. As the world continues to move swiftly towards AI, over-trust and dependency are breeding a new type of business leader that has surrendered executive function and authority over to the AI, without question. While a number of bias metrics have been proposed in recent years, no agreement on which metrics should be used and few available resources to operationalize them have been found. Regardless of recent attentiveness, auditing for bias when developing and deploying algorithmic decision-making systems is not yet standard practice (Salerio, 2018).

So with business leaders abdicating their executive function and authority to $\mathrm{AI}$, with its known biases, how will this be mitigated, and by whom? In the interim, the executive function, the brain command post in humans, is at risk of diminished capacity in the areas which regulate, control, and manage other cognitive processes, such as foresight and planning, operational memory, concentration, analytics, verbal reasoning, inhibition and discretion, mental flexibility, task switching, intentionality, purposefulness, and complex decision-making. Who's liable for decisions made and responsible for the consequences of those decisions - the AI itself?

We've entered a very serious time in business and society and there is a dire need for sound elevated executive functioning and collective judgment. Decision-making using AI must be interrogated by leaders, using standards and laws, to mitigate bias and to ensure leaders have the last say in the decision-making process. Additional research is needed to study the long term impact on the human executive function in the age of AI.

\section{Implications to Managers}

Alarms are sounding regarding AI's potential to turn the workforce upside down. Managers will have to adapt to being led by intelligent machines, by (1) leaving repetitive tasks to AI; (2) focusing on judgment work; (3) treating intelligent machines as colleagues; and (4) harnessing the creativity of others in a diverse and integrated fashion (Kolbjornsrud, Amico, \& Thomas, 2016). This shift in leadership roles will certainly have a direct effect on the executive function and authority of today's leaders. To get ahead of the vast changes, the following recommendations are provided:

- Explore early. To navigate in an uncertain future, leaders must redefine their roles. In addition, they must set forth laws and regulations to guide the boundaries for AI's use in decision-making, its interaction, consequences, and impact on humans.

- Adopt clear performance indicators to drive the interrogation of AI. AI interrogation will raise the trust levels by eradicating or minimizing bias in the decision-making processes.

- Develop training and recruitment strategies for enhanced human executive functioning and intelligence. Leaders should develop a diverse workforce and team of leaders that balance creativity, fluid, crystallized, and social intelligence with analytical skills, - each side complementing the other to support sound elevated executive functioning and collective judgment.

AI's approaching disruptions are not likely to arrive all at once. The momentum of development is rapid and the repercussions more extensive than most executives and managers recognize. Leaders who have foresight into the future posture of the workforce can prepare themselves for the advent and dominance of AI. Moreover, it can be seen as an opportunity to thrive.

\section{Future Research}

AI algorithm models can spread into fields other than what they were originally created for. This peril is mounting, yet the financial industry serves as a warning. In a nut shell, AI algorithms should be interrogated prior to use in decision making to prevent bias, opaqueness, scale, and harm. Replacing human cognition with AI will create dependencies with great consequences. This along with scale is of great concern and warrants additional research. In addition, research is needed to study the long term impact on the human executive function in the age of AI. 


\section{References}

Albarghouthi, A., D’Antoni, L., Drews, S., \& Nori, A. (2017). Quantifying Program Bias. $A r X-$ $i v: 1702.05437$ [Cs]. Retrieved from http://arxiv. org/abs/1702.05437

Armstrong, S., Sotala, K., \& Ó hÉigeartaigh, S. S. (2014). The errors, insights and lessons of famous AI predictions - and what they mean for the future. Journal of Experimental \& Theoretical Artificial Intelligence, 26(3), 317-342. https://doi.org/10 $\underline{.1080 / 0952813 X .2014 .895105}$

Aslanyan, G., \& Porwal, U. (2018). Direct estimation of position bias for unbiased learning-to-rank without intervention. ArXiv:1812.09338 [Cs]. Retrieved from http://arxiv.org/abs/1812.09338

Banavar, G. (2016). What it will take for us to trust AI. Harvard Business Review.

Briner, R. B., Denyer, D., \& Rousseau, D. M. (2009). Evidence-based management: Concept cleanup time? Academy of Management Perspectives, 23(4), 19-32

Caliskan, A., Bryson, J. J., \& Narayanan, A. (2017). Semantics derived automatically from language corpora contain human-like biases. Science, 356(6334), 183-186. https://doi.org/10.1126/science.aal4230

Chamorro-Premuzic, M. T., Wade, M., \& Jordan, J. (2018). As AI Makes More Decisions, the Nature of Leadership Will Change. Harvard Business Review. Retrieved from https://hbr.org/2018/01/ as-ai-makes-more-decisions-the-nature-of-leadership-will-change

Chowdhury, R., \& Mulani, N. (2018). Auditing algorithms for bias. Harvard Business Review.

Cohen, M. S. (2013). Decision making "biases" and support for assumption-based higher-order reasoning. arXiv preprint arXiv:1304.1499.

Denyer, D., Tranfield, D., \& Van Aken, J. E. (2008). Developing design propositions through research synthesis. Organization Studies, 29(3), 393-413. doi:10.1177/0170840607088020

Dobbe, R., Dean, S., Gilbert, T., \& Kohli, N. (2018). A broader view on bias in automated decision-making: Reflecting on epistemology and dynamics. ArXiv:1807.00553 [Cs, Math, Stat]. Retrieved from http://arxiv.org/abs/1807.00553

Edge. (1997). Darwin among the machines; or, the origins of [artificial] life. Retrieved from https:// www.edge.org/conversation/george dyson-darwin-among-the-machines-or-the-origins- of-artificial-life

Epstein, Z., Payne, B. H., Shen, J. H., Dubey, A., Felbo, B., Groh, M., ... Rahwan, I. (2018). Closing the AI knowledge gap. ArXiv:1803.07233 [Cs]. Retrieved from http://arxiv.org/abs/1803.07233

Garcia, M. (2016). Racist in the machine: The disturbing implications of algorithmic bias. World Policy Journal, 33(4), 111-117. Retrieved from https://doi.org/10.1215/07402775-3813015

Gordon-Murnane, L. (n.d.). Ethical, Explainable Artificial Intelligence, 9.

Gough, D. (2007). Weight of evidence: A framework for the appraisal of the quality and relevance of evidence. Research Papers in Education, 22(2), 213-228. doi:10.1080/02671520701296189

Granados, L. (n.d.). Computers aren't bigotedthey're just based on cold calculations, right?, 3.

Johnson, J. L., \& Burton, B. K. (1994). Chaos and complexity theory for management: Caveat emptor. Journal of Management Inquiry, 3(4), 320328. https://doi.org/10.1177/105649269434005

Kolbjørnsrud, V., Amico, R., \& Thomas, R. J. (2016). How artificial intelligence will redefine management. Harvard Business Review, 2.

Lanka, S., \& Wu, T. (2018). ARCHER: Aggressive Rewards to Counter bias in Hindsight Experience Replay. ArXiv:1809.02070 [Cs, Stat]. Retrieved from http://arxiv.org/abs/1809.02070

Levendowski, A. (2018). How copyright law can fix artificial intelligence's implicit bias problem. Washington Law Review, 93, 579.

Miller, F. A., Katz, J. H., \& Gans, R. (2018). The OD Imperative to add inclusion to the algorithms of artificial intelligence. OD PRACTITIONER 50(1), 8.

Miller, T. (2018). Explanation in artificial intelligence: Insights from the social sciences. Artificial Intelligence, 267, 1-38. https://doi.org/10.1016/j. artint.2018.07.007

Montes, G. A., \& Goertzel, B. (2018). Distributed, decentralized, and democratized artificial intelligence. Technological Forecasting and Social Change, 141, 354-358 https://doi.org/10.1016/j. techfore.2018.11.010

Potapov, A., \& Rodionov, S. (2014a). Universal empathy and ethical bias for artificial general intelligence. Journal of Experimental \& Theoretical Artificial Intelligence, 26(3), 405-416. https://doi.org/1 $\underline{0.1080 / 0952813 X .2014 .895112}$

Pracana, C., Wang, M., \& World Institute for Advanced Research and Science (WIARS) (Portugal). (2016). International Psychological Applications Conference and Trends (InPACT) 2016 (Lisbon, Portugal, April 30-May 2, 2016).

Saini, V., \& Berg, K. (2018). Using artificial intelligence technology for social determinants and 
risk factors surveillance. International Journal of Population Data Science, 3(4). https://doi. org/10.23889/ijpds.v3i4.963

Saleiro, P., Kuester, B., Stevens, A., Anisfeld, A., Hinkson, L., London, J., \& Ghani, R. (2018). Aequitas: A Bias and Fairness Audit Toolkit. $A r X-$ $i v: 1811.05577$ [Cs]. Retrieved from http://arxiv. org/abs/1811.05577

Schrage, M. (4). Models for using AI to make decisions. Harvard Business Review. Retrieved from https://hbr.org/2017/01/4-models-for-using-aito-make-decisions

Shein, E. (2018). The dangers of automating social programs. Communications of the ACM, 61(10), 17-19. https://doi.org/10.1145/3264627

Strauß, S. (2018). From big data to deep learning: A leap towards strong AI or 'Intelligentia Obscura'? Big Data and Cognitive Computing, 2(3), 16. https://doi.org/10.3390/bdcc2030016

Sutton, A., Lansdall-Welfare, T., \& Cristianini, N. (2018). Biased Embeddings from Wild Data: Measuring, Understanding and Removing. $A r X-$ iv:1806.06301 [Cs, Stat]. Retrieved from http:// arxiv.org/abs/1806.06301

Temming, M. (n.d.). A new drive to revamp artificial intelligence may cut down bias, 5 . van Otterlo, M. (2018). Gatekeeping Algorithms with Human Ethical Bias: The Ethics of Algorithms in Archives, Libraries and Society. arXiv preprint arXiv:1801.01705. Retrieved from https://www. theguardian.com/technology/2016/jun/25/gpshorror-stories-driving-satnav-greg-milner

The Guardian. (2018). Franken-algorithms: the deadly consequences of unpredictable code. Retrieved from https://www.theguardian.com/technology/2018/aug/29/coding-algorithms-frankenalgos-program-danger

Wagner, A. R., Borenstein, J., \& Howard, A. (2018). Overtrust in the robotic age. Communications of the ACM, 61(9), 22-24. https://doi. org/10.1145/3241365.

Walker, R. (2017). Artificial Intelligence in Business: Balancing Risk and Reward. Retrieved from https://www.pega.com/artificial-intelligence-business-balancing-risk-and-reward

Review
This article was accepted under the strict peer re-
view option. For futher details, see the descrip-
tions at:
http://mumabusinessreview.org/peer-review-op-
tions/

\section{Author}

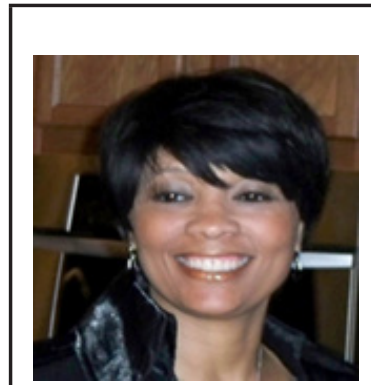

Tamie Santiago retired in 2015 as an Executive with over 34 years of expertise and leadership with the Department of Defense, White House, and the private sector, very skilled in leading, directing, and managing large complex organizations and systems. She has an outstanding background in cyber security, critical infrastructure, intelligence, information assurance, information technology management, strategic planning, research and analysis, fiscal management and oversight. She is currently an Associate Collegiate Professor of the Graduate School Cyber Security \& Information Assurance Department for the University of Maryland University College, where she is also a Doctorial Candidate. She has a Masters in Technology Management \& a Bachelors of Science Degree in Computer Information Systems Science from UMUC. 